\title{
Textos Informativos no AVA: Praticando Leitura e Interpretação nas Aulas de Química do Ensino Médio
}

\section{Informative Texts in the VLE: Practicing Reading and Interpretation in High School Chemistry Classes}

\author{
CILÉIA RODRIGUES \\ Universidade Federal de Santa Maria - UFSM \\ DANIELE CORREIA \\ Universidade Federal do Mato Grosso do Sul - UFMS \\ RICARDO ANDREAS SAUERWEIN \\ Universidade Federal de Santa Maria - UFSM
}

\begin{abstract}
Resumo: Neste trabalho, apresentamos um conjunto de atividades de leitura, desenvolvidas com estudantes da $3^{a}$ série do Ensino Médio de uma escola da rede pública de ensino, por meio da qual procuramos desenvolver as habilidades de leitura e interpretação. Desta forma, utilizamos textos de caráter informativo que trouxeram assuntos e curiosidades relacionados aos conteúdos de Química Orgânica. Para a realização dessas atividades de leitura, pensamos em uma abordagem que estivesse inserida no cotidiano dos estudantes e que estimulasse suas autonomias perante o processo de aprendizagem. Assim, as atividades foram disponibilizadas aos estudantes em um site administrado pelos autores. Os resultados apontam que os discentes apresentam baixa proficiência em leitura e interpretação. Contudo, tais dificuldades parecem poder ser superadas com a inserção de atividades sistemáticas e periódicas de leitura relacionadas a assuntos relevantes à formação dos alunos.
\end{abstract}

Palavras-chave: Leitura e Interpretação. Ensino de Química. TDIC.

\begin{abstract}
In this work, we present a set of reading activities, developed with students of the 3rd level of High School in a public school, with which we tried to develop reading and interpretation skills in Chemistry lessons. We have used texts of informative nature that addressed topics and curiosities related to the contents of Organic Chemistry. In order to carry out these activities, we developed an approach that could be present in the students' daily lives and that would stimulate their autonomy in the learning process. The reading activities were accessible to students on a website managed by the authors. The results show that the students have low proficiency in reading and interpretation. However, such difficulties seem to be overcome with the insertion of systematic and periodic reading activities related to subjects relevant to the education of students.
\end{abstract}

Keywords: Reading. Interpretation. Chemistry teaching. ICDT.

RODRIGUES, Ciléia; CORREIA, Daniele; SAUERWEIN, Ricardo, Andreas. Textos Informativos no AVA: Praticando Leitura e Interpretação nas Áulas de Qú́mica do'Ensino Médio. Informática na Éducação: teoria \& prática, Porto Alegre, v. 23, n. 2, p. 67-86, maio./ago. 2020 . 


\section{Introdução}

Como educadores, deparamo-nos com o constante desafio da busca por meios que auxiliem na aprendizagem dos nossos alunos. Tarefa árdua, pois são diversas as dificuldades apresentadas por cada um deles, cabendo a nós a capacidade de compreender, analisar e procurar atividades que viabilizem o seu desenvolvimento cognitivo, humano e cidadão, para torná-los capazes de atuar de forma relevante na sociedade.

Acreditamos que um dos caminhos para promover essas habilidades e competências é o incentivo à leitura. Considerando que a escola é um ambiente privilegiado de socialização do saber, é seu dever oferecer aos estudantes a aquisição de conhecimentos, não apenas de caráter informativo, mas também valorativo (FERREIRA; QUEIROZ, 2011).

Nesse contexto, entendemos que o Ensino Médio (EM) é a etapa da escolarização em que os jovens assumem uma maior preocupação com a sociedade e com os problemas que a envolvem, inserindo-se em debates sobre o destino do país e a difícil arte de posicionar-se de forma autônoma e crítica sobre questões sociais, ambientais e científicas da atualidade. No entanto, para que o estudante desenvolva pensamento e posicionamento crítico é fundamental que, em sua formação escolar, seja incentivado a ler e encontrar sentido e interesse na leitura, para que dessa forma seja capaz de compreender textos informativos, pois o ensino de Ciências aborda assuntos relacionados ao meio ambiente, à saúde etc. Para Isabel Solé

\footnotetext{
Aprender a ler significa aprender a encontrar sentido e interesse na leitura. Significa aprender a se considerar competente para a realização de tarefas de leitura e a sentir a experiência emocional gratificante da aprendizagem. Aprender a ler também significa aprender a ser ativo ante a leitura, ter objetivos para ela, se autointerrogar sobre o conteúdo e a própria compreensão (SOLÉ, 1998, p.172).
}

Não é incomum em sua prática docente o professor se deparar com situações em que aluno manifesta suas dúvidas na forma de: "Professora, não entendi o exercício 2 ...". Ao dialogar com o aluno, o professor percebe que o problema não é conceitual, mas de leitura e interpretação, o que é muito mais preocupante. Portanto, é imprescindível que em sala de aula o professor de Química utilize estratégias que incentivem o desenvolvimento da leitura e interpretação por parte de seus alunos, pois sem estas competências o aluno pode apresentar dificuldades na aprendizagem de conceitos científicos.

De acordo com os últimos dados do Indicador de Analfabetismo Funcional (INAF), de 2018, $29 \%$ da população brasileira é considerada Analfabeto Funcional ${ }^{1}$, sendo que este número representa um aumento de $2 \%$ em relação à última pesquisa realizada, no ano de 2015 (INAF BRASIL, 2018). Calçade (2019) discute a alfabetização no Brasil e cita a fala da pesquisadora e

\footnotetext{
${ }^{1}$ Analfabetismo Funcional: É caracterizado pela incapacidade do indivíduo em compreender, utilizar e refletir sobre informações escritas e também a inabilidade em desenvolver raciocínio matemático que atendam as demandas do cotidiano. BRASIL. Indicador de Alfabetismo Funcional. Relatório de Resultados Preliminares 2018. Disponível em: <https://drive.google.com/file/d/1ez-6jrlrRRUm9JJ3MkwxEUffltjCTEI6/view> Acesso em: 12 de jul. 2020
} 
professora Silvia Colello, que diz que este fato pode ser explicado por problemas sociais e econômicos, mas também por um ensino pouco significativo, com práticas inadequadas de leitura e escrita, o que acaba por desestimular os alunos, podendo provocar até mesmo a evasão escolar (CALÇADE, 2019).

A situação é preocupante, o que nos leva ao questionamento: Afinal, o que está acontecendo com os estudantes brasileiros para apresentarem baixa proficiência em leitura? Uma das possíveis respostas para este questionamento é a forma como os textos são apresentados aos alunos. Para Kleiman (2004), a leitura foi aplicada de forma incorreta desde as séries iniciais, ou seja, as escolas utilizavam os textos com o objetivo de trabalhar grupos gramaticais separadamente e de forma desconexa, dessa forma retirou-se a mensagem do texto por meio da assimilação e da compreensão de cada palavra, uma por uma. Perde-se assim, a essência do texto, pois elementos isolados não têm significação. Outro fato apontado é de que os textos trabalhados não trazem elementos com os quais os estudantes estejam familiarizados. Para Liberato e Fulgêncio (2007, p. 14), "é possível que o leitor não consiga ler um texto que, embora escrito numa língua que ele domina, trate de um assunto sobre o qual ele não tem informações".

Uma das maiores pesquisas em âmbito nacional sobre o hábito da leitura, Retratos da leitura no Brasil, que tem por objetivo conhecer o perfil do leitor e não leitor e o comportamento leitor medindo intensidade, forma, limitações, motivação, representações e condições de leitura e de acesso ao livro - impresso e digital - pela população brasileira, aponta, em sua última edição, que $44 \%$ da população não lê (RETRATOS DA LEITURA NO BRASIL, 2016). Dentre as variadas justificativas para isso se destacam a falta de tempo (32\%) e não gostar de ler (28\%). A mesma pesquisa questionou os entrevistados sobre o que faziam em seu tempo livre e $47 \%$ responderam que usam a internet, $44 \%$ usam o WhatsApp e 35\% usam Twitter ou Instagram.

Não há como negar que redes sociais, Facebook, Instagram, WhatsApp, etc. fazem parte da rotina dos estudantes. Quando o professor se utiliza deste universo cultural digital para fins didáticos, poderá estar proporcionado momentos de aprendizagem significativos para 0 estudante. Assim, entendemos que as Tecnologias Digitais de Informação e Comunicação (TDIC) são ferramentas que podem ser articuladas às práticas que visam a formação do leitor, ou seja, o incentivo ao hábito de ler e o desenvolvimento de habilidades relacionadas à leitura, interpretação e escrita por parte dos estudantes.

Nessa perspectiva, a presente pesquisa relata e analisa uma proposta didática que envolveu a aplicação de seis textos de caráter informativo relacionados a conteúdos de Química Orgânica, a qual foi desenvolvida com estudantes da $3^{a}$ série do EM de uma Escola Pública do interior do Rio Grande do Sul. Assim, propomo-nos a investigar se as práticas de leitura e a forma como elas foram disponibilizadas aos alunos, possibilitaram o desenvolvimento de habilidades de leitura, interpretação e compreensão dos conteúdos químicos trabalhados: Funções Orgânicas e Propriedades Físico-Químicas dos Compostos Orgânicos. A coleta de dados se deu por meio da análise das respostas dos alunos às atividades de leitura e ao questionário realizado ao final da intervenção pedagógica. 


\section{Leitura, TIC e Formação de Cidadãos Leitores: tecendo relações}

É inegável que possuir as habilidades de leitura e interpretação é um requisito de suma importância para qualquer cidadão, especialmente para os que ainda estão em fase de formação, como os estudantes da Educação Básica. A formação de cidadãos ativos e críticos, que consigam se posicionar perante a sociedade em que vivem, é um dos principais desafios para os docentes e escolas. Para Paulo Freire (2006), o ato de ler liberta o homem, pois the fornece condições de compreender o mundo e refletir sobre sua condição, transformando suas concepções e também o meio em que vive. Ainda, segundo Kleiman, a leitura concede, dentre outras coisas:

[...] a interação à distância, com um interlocutor não imediatamente acessível e que já construiu seu texto sem a intervenção imediata, direta do leitor. Esse tipo de interação é essencial para a aprendizagem ou este estaria limitado àquilo que é imediatamente acessível aos nossos sentidos (KLEIMAN, 2004, p. 7).

Contudo, fica a pergunta: o que é ler? Para Solé (1998), a leitura é um processo de interação entre o leitor e o texto, em que se tenta satisfazer os objetivos que guiam sua leitura, pois sempre se lê com alguma finalidade, seja ela de lazer ou aprendizado. Segundo a autora, a interpretação que damos a um texto depende em grande parte do objetivo da nossa leitura, o que faz com que dois leitores diferentes possam dar interpretações distintas ao mesmo texto, até certo ponto. Portanto, tal aspecto deve ser levado em consideração ao ensinarmos nossos alunos todo o processo de leitura.

Nessa perspectiva, acreditamos que a prática da leitura seja compromisso de todas as áreas do conhecimento, inclusive a do professor de Química pois, na sociedade atual, em que a ciência se tornou uma das maiores conquistas da nossa cultura e contribui para o seu desenvolvimento, temos a necessidade de compreender e apreciar o conhecimento científico. Possivelmente, a aproximação entre a sociedade e a Ciência possibilitará que os indivíduos sejam capazes de interpretar criticamente as notícias que Ihes são apresentadas todos os dias pelos meios de comunicação, sobre saúde, meio ambiente, etc. Caso contrário, esses sujeitos correm o risco de se tornarem pessoas anuladas perante a sociedade em que vivem, devido à incapacidade de compreender o mundo que os cerca.

A forma como os textos se apresentam enquanto unidades comunicativas, assim como as características que neles constam, podem manifestar diferentes intenções, tais como: informar, entreter, convencer, etc. Os textos escolhidos para as práticas de leitura da nossa proposta didática foram retirados da internet e têm função informativa, apesar de não serem textos escolares ou escritos diretamente para os estudantes. Isto se dá pelo fato de que este trabalho tem por finalidade melhorar a leitura e a interpretação dos estudantes através de textos que se inter-relacionem e complementem os conteúdos da disciplina de Química.

Em relação às TDIC no contexto educacional, Giordan (2015) aborda que algumas experiências pedagógicas com uso das TDIC estão sendo desenvolvidas por professores e alunos. Contudo, isso ainda não é uma prática comum nas escolas, tendo como causas um currículo extenso, enciclopédico e com poucas aulas semanais. $O$ autor destaca que tem a expectativa de 
que, com as reformas curriculares, as escolas sejam motivadas a permear as fronteiras da sala de aula para atingir o ciberespaço, a fim de que professores e alunos possam usufruir com criatividade e autonomia essa dimensão tecnológica.

No ensino de Química, alguns estudos recentes (PAULA et al., 2014; PAULETTI, ROSA e CATELLI, 2014; LEITE, 2015; SANTOS JUNIOR et al., 2016; MACHADO, 2016; MORENO e HEIDELMANN, 2017) apontam que existem várias TDIC disponíveis para a sua aplicação no ensino e também apresentam metodologias pedagógicas com o uso dessas tecnologias, que podem trazer alternativas viáveis para a incorporação efetiva desses recursos em sala de aula.

Moreno e Heidelmann (2017) realizaram uma investigação e seleção de recursos tecnológicos aplicados ao ensino de química, tendo como critérios de análise: a facilidade de uso dos aplicativos; a flexibilidade dos aplicativos a fim de serem compatíveis com os equipamentos dispostos em sala de aula, isto é, com os sistemas operacionais; o acesso gratuito ou os custos reduzidos e a organização das ferramentas dispostas nos aplicativos. Como resultado da compilação desses recursos tecnológicos, os autores caracterizam os aplicativos de acordo com as suas funcionalidades, organizando-os e tecendo alguns comentários sobre eles em seu artigo, destacando os aplicativos para a criação de formulários de pesquisa online, edição de fórmulas químicas e moléculas, criação de ambientes virtuais de aprendizado, recursos com jogos e simulações. Concluindo, os autores consideram que o uso desses recursos tecnológicos pelos professores promove a construção de uma aula mais interessante, direcionada a uma realidade que instiga o aluno ao estudo, bem como favorece maior auxílio para acompanhamento de atividades escolares.

Neste sentido, para a elaboração das práticas de leitura, utilizamos um Sistema de Gerenciamento de Conteúdo (CMS - Content Management System) chamado Drupal, que pode ser conceituado como um site pré-estruturado usado para criar, editar, gerenciar e publicar conteúdo de forma consistentemente organizada, permitindo que ele seja modificado, removido e adicionado com facilidade. De fácil instalação e configuração, conta com possibilidade de construção de blogs, ferramentas colaborativas e software de comunidades baseado em discussões.

A escolha deste site é justificada pelo fato de que, além das vantagens já mencionadas, entendemos que o uso de um Ambiente Virtual de Aprendizagem (AVA) possibilita uma interessante estratégia para o processo de ensino e aprendizagem, pois viabiliza um ambiente diferenciado em que o estudante pode realizar as tarefas em casa, no momento em que melhor Ihe aprouver, contribuindo, desta forma, para o desenvolvimento da sua autonomia. Além disso, ao utilizarmos este sistema economizamos em uma quantidade significativa de impressões, contribuindo com as causas ambientais e ainda diminuindo custos.

\section{Encaminhamentos Metodológicos}

A proposta didática foi desenvolvida com alunos da $3^{a}$ Série do EM de uma escola pública do interior do Rio Grande do Sul. Nas atividades de leitura foram utilizados seis textos retirados da 
internet. Eles são de caráter informativo, isto é, abordaram conteúdos químicos na forma de curiosidades, notícias e informações. A seleção e aplicação dos textos se deu em função do conteúdo de Química Orgânica que estava sendo ministrado pela docente responsável pela turma.

A escolha do uso de textos midiáticos de caráter informativo, bem como o fato de as atividades serem desenvolvidas em AVA se baseia na ideia de que vivemos em um momento de revisão da educação escolar, de seu papel e de seu alcance. Todavia, não basta apenas estimular a leitura, a escrita e a interpretação e continuar usando as mesmas metodologias com as quais estamos acostumados. É preciso lançar-se a novos desafios, elaborando práticas que estejam inseridas no contexto atual, utilizando outras formas de comunicação e diferentes ferramentas. Deste modo, os textos foram expostos em um site desenvolvido por um dos autores deste artigo e administrado por uma das autoras do trabalho, que era professora regente da turma. O site possuía acesso restrito aos estudantes e administradores.

Para a leitura e interpretação dos textos, utilizou-se uma estratégia de leitura que consiste em dar títulos a cada parágrafo do texto, de forma que os alunos, ao lerem seus títulos, conseguissem expressar com suas palavras a ideia principal do parágrafo. Além disso, propusemos questões interpretativas categorizadas de acordo com o trabalho de Menegassi (2010): a) Perguntas de resposta textual, que são aquelas cujas respostas são encontradas de forma direta e explícita no texto; b) Perguntas de resposta inferencial, em que o estudante necessita estabelecer relações do texto e as informações que possui em seu conhecimento prévio; c) Perguntas de resposta interpretativa, nas quais o aluno precisa elaborar uma resposta pessoal.

A análise dos títulos e das respostas dadas às questões pelos alunos foi fundamentada no procedimento de análise de conteúdo proposta por Bardin (2004). Essa metodologia é estruturada em três polos cronológicos: a) Pré-análise; b) Exploração do material e c) Tratamento dos resultados, inferência e interpretação. Para a autora, a pré-análise é um período de organização em que instituem-se diretrizes que devem ser flexíveis para que possam ser alteradas no decorrer do trabalho. Em um primeiro momento, se estabelece um contato com os documentos de análise, "deixando-se invadir por impressões e orientações". A partir desse primeiro contato, define-se o corpus, que é o conjunto de documentos que serão submetidos aos procedimentos analíticos. A exploração do material é a fase de sistematizar as decisões estabelecidas na pré-análise, ou seja, colocar em prática o que foi planejado. A fase de tratamento corresponde ao momento em que os resultados obtidos são tornados significativos e válidos (BARDIN, 2004).

Dessa maneira, o presente trabalho apresenta uma pesquisa qualitativa, na qual os dados obtidos foram analisados no intuito de verificar as habilidades de leitura e interpretação dos discentes e proporcionar alternativas para aprimorar tais habilidades, por meio de práticas de leituras sistemáticas e periódicas.

Em um primeiro momento foi construído o AVA, onde todos os textos e atividades foram disponibilizados aos alunos. Para a realização das atividades, os alunos deveriam possuir um e- 
mail para ser cadastrado no ambiente. Após o cadastro, os estudantes recebiam um usuário e uma senha para poder entrar no AVA e então realizar as atividades de leitura, que consistia em dar títulos aos parágrafos que compunham o texto e responder as questões sobre o mesmo. Após a atividade ser postada no ambiente, os estudantes possuíam um prazo de 7 dias para concluí-la. A seguir, ocorria a análise das respostas pela docente. Em sala de aula, após devolução das atividades de leitura para os alunos, ocorria a discussão das mesmas com ênfase no conteúdo químico que estava sendo abordado.

Neste artigo, serão analisados os títulos dados por uma turma de ensino médio composta por 15 estudantes, ao primeiro e último texto, suas respostas a duas questões de interpretação e ao questionário proposto ao final das práticas de leitura. A alguns pode parecer um número pequeno de estudantes, contudo isso é uma característica muito comum em escolas de cidades pequenas do interior. No Quadro 1, constam o título dos textos trabalhados, o assunto de Química que foi explorado em aula e a metodologia de ensino utilizada para discussão do texto e abordagem do conteúdo:

Quadro 1 - Resumo dos Textos Desenvolvidos.

\begin{tabular}{|c|c|c|}
\hline Texto & Síntese do texto & $\begin{array}{l}\text { Conteúdo Químico } \\
\text { Abordado }\end{array}$ \\
\hline O que é petróleo? & $\begin{array}{l}\text { Discute como o petróleo se forma, as } \\
\text { ferramentas e métodos que são utilizados } \\
\text { desde a sua localização até sua distribuição. }\end{array}$ & Hidrocarbonetos \\
\hline O álcool e suas aplicações & $\begin{array}{l}\text { Propriedades físico-químicas do etanol, bem } \\
\text { como sua extração e produção. }\end{array}$ & Álcoois \\
\hline $\begin{array}{l}\text { Para acabar com a } \\
\text { choradeira na cozinha }\end{array}$ & $\begin{array}{l}\text { Explicação das substâncias químicas que são } \\
\text { liberadas quando temperos como alho e } \\
\text { cebolas são cortados. }\end{array}$ & $\begin{array}{l}\text { Funções Orgânicas } \\
\text { Oxigenadas e } \\
\text { Sulfuradas }\end{array}$ \\
\hline $\begin{array}{l}\text { Maconha sintética e a era } \\
\text { das drogas de laboratório }\end{array}$ & $\begin{array}{l}\text { Notícia que relata como traficantes nos } \\
\text { Estados Unidos tentam burlar a fiscalização } \\
\text { disfarçando drogas como maconha e cocaína } \\
\text { na forma de incenso e sais de banho. }\end{array}$ & $\begin{array}{l}\text { Funções Orgânicas } \\
\text { Nitrogenadas }\end{array}$ \\
\hline A gota que faltava & $\begin{array}{l}\text { Trata sobre a questão da falta de água no } \\
\text { estado de São Paulo, causas e consequências } \\
\text { e sobre a previsão nada animadora de } \\
\text { pesquisadores no assunto. }\end{array}$ & $\begin{array}{l}\text { Solubilidade dos } \\
\text { Compostos Orgânicos }\end{array}$ \\
\hline A química do mau cheiro & $\begin{array}{l}\text { Discute como nosso sistema olfatório } \\
\text { identifica o cheiro e o classifica como bom ou } \\
\text { ruim e como nosso cérebro registra esta } \\
\text { informação. }\end{array}$ & $\begin{array}{l}\text { Ligações } \\
\text { Intermoleculares }\end{array}$ \\
\hline
\end{tabular}




\section{Análise e Discussão dos Resultados}

A seguir, analisaremos os títulos dados pelos alunos a um parágrafo retirado do Texto 1: "O que é petróleo?". Os estudantes foram identificados por números e as transcrições são uma cópia fiel dos títulos dados por eles, portanto, não houve correções ortográficas e gramaticais. Abaixo segue a transcrição de um parágrafo do Texto 1 e, no Quadro 2, os títulos dados pelos alunos a este mesmo parágrafo:

"[...] Aos detritos de rochas, resultantes da erosão da crosta terrestre pela ação da natureza, dáse o nome de sedimentos. Por longo tempo, os sedimentos foram se acumulando em camadas, dando origem às rochas sedimentares. O petróleo só poderá ser encontrado em áreas onde houve acumulação de restos orgânicos e rochas sedimentares. Todavia, depois de formado, o petróleo não se acumula na rocha em que foi gerado. Ele passa através dos poros das rochas, até encontrar uma outra rocha que o aprisione, formando a jazida. No entanto, isso não significa que toda rocha sedimentar contenha uma jazida. Sua busca é tarefa árdua, difícil e exige muita paciência $[\ldots] "$..

Quadro 2 - Títulos dados pelos estudantes ao parágrafo do texto.

\begin{tabular}{|c|l|}
\hline Estudante & \\
\hline 1 & Orítulos \\
\hline 2 & Petróleo não há acumulação em rochas. \\
\hline 3 & Difícil e longa formação petrológica. \\
\hline 4 & A base de resíduos. \\
\hline 5 & Com certas adaptações um complementa o outro. \\
\hline 6 & A procura por ele. \\
\hline 7 & É preciso paciência. \\
\hline 8 & Local de armazenamento petrolífero. \\
\hline 13 & O acumulo do petróleo \\
\hline 10 & Origem do PETRÓLEO. \\
\hline 11 & Longa e difícil formação. \\
\hline 12 & o que gera e o que aprisiona que podemos encontra-lo \\
\hline
\end{tabular}




\begin{tabular}{|c|l|}
\hline 14 & Originação e difícil acesso. \\
\hline 15 & Formação e armazenamento do Petróleo. \\
\hline
\end{tabular}

Fonte: Os autores

Com base na leitura e análise dos títulos dados pelos estudantes, percebemos que eles apresentaram dificuldade de interpretação e em expressar a ideia principal do parágrafo. Segundo Solé (1998), "a ideia principal resulta da combinação entre os objetivos da leitura que guiam o leitor, entre os seus conhecimentos prévios e a informação que o autor queira transmitir".

Os títulos dados pelos Estudantes 1, 5, 6 e 7 não são inverdades, porém são noções um pouco vagas e amplas sobre o assunto. O Estudante 2 escolheu um título que não condiz com as informações contidas no trecho. Os títulos sugeridos pelos Estudantes 3 e 14 apresentam pouca coerência e difícil compreensão, além disso, utilizam palavras inexistentes, "petrológica" e "originação". Já nas respostas dadas pelos Estudantes 4 e 13, percebemos sua criatividade e esforço para expressar suas ideias, contudo faltou coerência na escolha das palavras, deixando suas respostas um tanto confusas. Percebemos que grande parte dos alunos apresentaram dificuldade em sintetizar de forma clara e coerente a ideia principal do parágrafo. Este resultado corrobora aqueles relatados por Correia, Decian, Sauerwein (2017) em uma atividade de leitura em sala de aula. Segundo as autoras, a dificuldade em expressar a ideia principal do parágrafo pode ser justificada pelo pouco hábito de leitura e escrita dos estudantes.

Por outro lado, os títulos escolhidos pelos Estudantes 8, 9, 10, 11, 12 e 15 revelam que os alunos expressaram com suas próprias palavras a ideia principal do parágrafo. Como pode ser visto nesses excertos, os alunos produziram suas sínteses na perspectiva de interpretação defendida por Solé (1998), em que a síntese da ideia principal é o resultado do diálogo interativo entre as ideias do autor e do leitor.

Após a atividade de dar título ao parágrafo do Texto 1 , os alunos responderam questões interpretativas a respeito do mesmo. No Quadro 3, estão dispostas as respostas dadas à Questão: "O que é uma jazida de petróleo?"

Quadro 3 - Respostas dos estudantes referentes à questão de interpretação.

\begin{tabular}{|c|l|}
\hline Estudante & \multicolumn{1}{|c|}{ Respostas } \\
\hline 1 & $\begin{array}{l}\text { Ele passa através dos poros das rochas, até encontrar uma outra rocha } \\
\text { que o aprisione, formando a jazida. }\end{array}$ \\
\hline 2 & $\begin{array}{l}\text { Quando o petróleo se acumula em rochas que não foi formado, ele passa } \\
\text { através dos poros das rochas, até encontra uma que apresione até formar } \\
\text { a jazida, então a jazida é uma rocha que os poros são ocupados pelo } \\
\text { petróleo. }\end{array}$ \\
\hline
\end{tabular}




\begin{tabular}{|c|c|}
\hline 3 & $\begin{array}{l}\text { O petróleo ele só pode ser encontrado onde ouve acumulação de restos } \\
\text { orgânicos, onde após ser formado ele não se acumula onde foi gerado, } \\
\text { passa por poros, onde são ocupados pelo petróleo, assim denominando- } \\
\text { se JAZIDA. }\end{array}$ \\
\hline 4 & $\begin{array}{l}\text { Jazida de petróleo ocorre em rochas sedimentares, essas rochas são } \\
\text { permeáveis o óleo passa através delas pelo interior da crosta terrestre. }\end{array}$ \\
\hline 5 & $\begin{array}{l}\text { A jazida não e nada mais nada menos do que uma rocha cujos poros são } \\
\text { ocupados pelo petróleo. }\end{array}$ \\
\hline 6 & São onde se acumula os resíduos orgânicos formando assim o petróleo. \\
\hline 7 & $\begin{array}{l}\text { As jazidas de petróleo acontecem quando o petróleo passa de uma rocha } \\
\text { a outra, já que ele não fica aprisionado em uma única rocha. }\end{array}$ \\
\hline 8 & Jazida é onde se forma o petróleo. \\
\hline 9 & É o aprosionamento do petróleo Em uma rocha \\
\hline 10 & São rochas que aprisionam o petróleo. \\
\hline 11 & São onde se acumula os resíduos orgânicos, assim formando o petróleo. \\
\hline 12 & Algumas rochas onde o petróleo fica apresinado \\
\hline 13 & Jazida é uma substancia que ocorre naturalmente na rocha. \\
\hline 14 & São onde se acumula os resíduos orgânicos, assim formando o petróleo. \\
\hline 15 & $\begin{array}{l}\text { A jazida é uma rocha cujos poros acumulam o petróleo, ela está dentro de } \\
\text { uma outra rocha chamada "rocha sedimentar". Como diz o texto, nem } \\
\text { sempre uma rocha sedimentar vai possuir uma jazida. }\end{array}$ \\
\hline
\end{tabular}

Fonte: Os autores

A partir da análise das respostas dadas pelos discentes, constatamos que o Estudante 1 não conseguiu responder à questão com suas palavras e realizou a cópia literal de uma frase do parágrafo. De acordo com Ferreira e Queiroz (2011), isso ocorre devido à insegurança do aluno em explicitar sua interpretação e apresentar conceitos ou ideias equivocadas. Os Estudantes 2 e 3 apresentam certa dificuldade em organizar as informações e expressá-las com clareza. As respostas dos Estudantes 4, 6, 7, 8, 11, 13 e 14 revelam que os alunos tiveram dificuldades em interpretar as informações do parágrafo. As respostas dos Estudantes 5, 9, 10, 12 e 15 estão adequadas, apesar de apresentarem pequenos erros de escrita e pontuação (Estudantes 9 e 12) e não deixarem claro que a jazida é a rocha que aprisiona o petróleo (Estudantes 5 e 15).

A análise das respostas dispostas no Quadro 3 nos levam a algumas constatações importantes, por exemplo, o fato dos discentes apresentarem dificuldades para realizar a tarefa de dar títulos ao parágrafo, o que denota falta de poder de síntese. Também dificuldades para responder à questão de interpretação, vale destacar que a resposta à pergunta proposta poderia ser facilmente encontrada no parágrafo. 
Portanto, resultados como os relatados acima reforçam a importância de desenvolver práticas de leitura em sala de aula, especialmente, quando a leitura do texto vem associada a uma estratégia de leitura. As autoras Correia, Decian, Sauerwein (2017) ressaltam que a leitura do texto associada às estratégias de leitura promove a motivação e envolvimento dos alunos durante todo o processo de leitura e discussão do texto, bem como a vinculação entre as informações do texto e o conteúdo estudado. Neste sentido, a leitura do texto associada à estratégia de leitura de nomear parágrafos tem como propósito incentivar a leitura e a interpretação, a identificação da ideia principal e sua relação com o conteúdo estudado. Concordamos, com Correia, Decian, Sauerwein (2017), que as habilidades relacionadas às expressões oral e escrita só serão desenvolvidas com a inserção de práticas frequentes e periódicas de leitura. Portanto, a seguir relatamos os resultados da última prática de leitura, o Texto 6 "A química do mau cheiro". Abaixo segue a transcrição de um parágrafo do Texto 6 e no Quadro 4 os títulos dados pelos alunos a este mesmo parágrafo:

"[...] A interpretação fisiológica de um odor implica em julgar o quão forte, agradável ou desagradável ele é. Odores desagradáveis estão em geral associados a coisas desagradáveis. Embora um odor possa ser não tóxico, sua associação à decomposição biológica pode indicar algo a se evitar ou um eventual risco à saúde. É por essa interpretação fisiológica que registramos com maior propriedade os cheiros que nos causam essas sensações desagradáveis. Algumas substâncias - como a piridina (cheiro de peixe podre), o metanotiol (cheiro do gás de cozinha), escatol (cheiro de fezes), entre outras - remetem-nos a situações que lembram perigo ou um ambiente não muito saudável. Essas são características psicoculturais que nos fazem agir de maneira repulsiva ao mau cheiro $[\ldots]^{\prime \prime}$.

Quadro 4 - Títulos dados pelos estudantes ao parágrafo do texto.

\begin{tabular}{|c|l|}
\hline Estudante & \multicolumn{1}{c|}{ Títulos } \\
\hline 1 & Interpretação do odor \\
\hline 2 & Cheiros ruins influenciam na sua saúde. \\
\hline 3 & $\begin{array}{l}\text { o cheiro que sentimos são comandados pela nossa interpretação } \\
\text { fisiológica. }\end{array}$ \\
\hline 4 & Odor pode ter interpretação? \\
\hline 5 & $\begin{array}{l}\text { O desagradável nos causa impressões ruins, assim como o agradável } \\
\text { nos causa boas impressões }\end{array}$ \\
\hline 6 & A associação do mau cheiro com sua fonte. \\
\hline 7 & Fugindo do mau cheiro \\
\hline 9 & $\begin{array}{l}\text { Geralmente cheiros ruins nos levam a pensar que o ambiente não é } \\
\text { saudável. }\end{array}$ \\
\hline & Porque algumas substâncias não nos são agradáveis \\
\hline
\end{tabular}




\begin{tabular}{|l|l|}
\hline 10 & Porque temos repulsa a mau cheiro \\
\hline 11 & O motivo de agirmos de tal forma aos odores desagradáveis. \\
\hline 12 & Cheiros e sensações desagradáveis \\
\hline 13 & os maus cheiros nos alertam a riscos \\
\hline 14 & O que nos faz reagir contra o mal cheiro. \\
\hline 15 & $\begin{array}{l}\text { odores desagradáveis nos causam repulsão, pois sabemos que mau } \\
\text { cheiro é sinal de coisa ruim e desagradável }\end{array}$ \\
\hline
\end{tabular}

Fonte: Os autores

Por meio da leitura e análise dos títulos (Quadro 4) dados pelos alunos ao parágrafo, constamos que todos os estudantes conseguiram realizar a atividade com êxito. Pode-se observar que em todos os títulos há referência sobre a interpretação fisiológica do nosso corpo aos tipos de odores, que é a ideia central do parágrafo. Assim, em sua maioria, as respostas analisadas indicam que os estudantes conseguiram interpretar o parágrafo, expuseram suas ideias com clareza e coesão, utilizando frases de sua autoria e que destacam a ideia principal contida no trecho.

Como pode ser visto nos excertos do Quadro 4, os alunos produziram suas sínteses na perspectiva de interpretação defendida por Solé (1998). Fica evidente que as produções textuais dos alunos ilustram uma interpretação alternativa à apresentada no Texto 6, isto é, os alunos parecem ter percebido que a leitura prevê interação entre autor-texto-leitor. Salienta-se que essa postura não foi verificada nas duas primeiras práticas de leitura com texto informativo. Acreditamos que um dos fatores que possa ter influenciado nessa mudança foi o tema discutido no texto, ou seja, um assunto que foi considerado mais interessante e pertinente do que o apresentado nos textos anteriores.

Também se evidenciaram melhorias significativas tanto na qualidade das informações quanto na extensão das sínteses dos alunos. Isso fica explícito quando comparamos os Títulos dados pelo Estudante 2, que na primeira atividade de leitura apresentou um título com ideias incoerentes ao explicitado no texto e, nesta última, trouxe um título que sintetiza de maneira satisfatória a ideia principal.

O Texto 6 foi a última prática de leitura desenvolvida pelos alunos, ou seja, após os desafios e dificuldades apresentados na primeira atividade de leitura, observamos, pelos títulos dados ao Texto 6, uma mudança expressiva na postura de leitura dos alunos. Salientamos que as atividades com textos informativos foram inseridas regularmente ao longo do ano letivo, portanto, os avanços com relação aos modos de leitura foram se tornando mais explícitos principalmente a partir do Texto 3. Em contrapartida, durante o processo de implementação das práticas de leitura, em particular a partir do texto 3, percebemos que os estudantes modificaram seus modos de leitura, isto é, passaram a interagir com os textos durante todo o processo de leitura e discussão dos textos. Somando-se a isso, percebeu-se que os alunos começaram, especialmente a partir das duas últimas práticas de leitura, a se posicionar criticamente sobre as informações lidas, fato que foi evidenciado nas discussões em sala. 
Portanto, os avanços com relação às expressões oral e escrita dos estudantes, percebidos ao longo das implementações das atividades com textos informativos, dão indícios de que as leituras dos textos associadas à estratégia de leitura de dar títulos aos parágrafos potencializaram a contextualização e a abordagem dos conteúdos químicos, bem como a evolução dos alunos com relação à leitura e à escrita. Nessa direção, acreditamos que as mudanças observadas nos modos de leitura dos estudantes podem ser atribuídas, aparentemente, a uma possível ressignificação do ato de ler (RÖSING, 2003). Para Ferreira e Queiroz (2011), a evolução nas habilidades de leitura e escrita não ocorre de forma imediata, daí a importância da realização periódica das práticas de leitura em sala de aula.

Da mesma forma que na prática de leitura do Texto 1, propomos aos alunos no Texto 6 uma questão interpretativa:

"Qual tipo de cheiro é identificado de forma mais intensa pelo nosso cérebro e como ele o faz?"

As respostas a esta questão estão dispostas no Quadro 5.

Quadro 5 - Respostas dos estudantes referentes à questão de interpretação.

\begin{tabular}{|c|c|}
\hline Estudante & Respostas \\
\hline 1 & $\begin{array}{l}\text { Os desagradáveis, porque a presença de um mau odor em geral é um sinal } \\
\text { para que se evite sua fonte e É por essa interpretação fisiológica que } \\
\text { registramos com maior propriedade os cheiros que nos causam essas } \\
\text { sensações desagradáveis. }\end{array}$ \\
\hline 2 & $\begin{array}{l}\text { é o cheiro desagradavel pois quando sentimos vimos e saimos de perto } \\
\text { para nao afetar na nossa saude. }\end{array}$ \\
\hline 3 & $\begin{array}{l}\text { O mau cheiro. Por que registramos com maior propriedade os cheiros que } \\
\text { nos causam sensações ruins. }\end{array}$ \\
\hline 4 & $\begin{array}{l}\text { Registramos com maior propriedade os cheiros que nos causam sensações } \\
\text { desagradáveis. Algumas substâncias - como a piridina (cheiro de peixe } \\
\text { podre), o metanotiol (cheiro do gás de cozinha), escatol (cheiro de fezes), } \\
\text { entre outras - remetem-nos a situações que lembram perigo ou um } \\
\text { ambiente não muito saudável. Essas são características psicoculturais que } \\
\text { nos fazem agir de maneira repulsiva ao mau cheiro. }\end{array}$ \\
\hline 5 & $\begin{array}{l}\text { O desagradável pois o nosso cérebro identifica mais rápido o cheiro ruim } \\
\text { por ser um perigo ou ambiente que não é saudável. }\end{array}$ \\
\hline 6 & Os de mau cheiro, porque geralmente são fortes e nos remetem perigo. \\
\hline 7 & $\begin{array}{l}\text { Cheiros ruins. Nosso cérebro detecta os odores, um lembrete para evitar } \\
\text { sua fonte. É por essa interpretação fisiológica que nosso cérebro registra } \\
\text { com maior propriedade os cheiros que causam essas desagradáveis } \\
\text { sensações. }\end{array}$ \\
\hline 8 & $\begin{array}{l}\text { Os cheiros mais desagradáveis são os quais mais sentimos, e elas nos } \\
\text { fazem lembrar que estamos em perigo ou em ambientes não saudáveis } \\
\text { por isso tendemos a sair do local. }\end{array}$ \\
\hline
\end{tabular}




\begin{tabular}{|c|l|}
\hline 9 & Os cheiros ruins, pois servem de alerta à possíveis perigos. \\
\hline 10 & $\begin{array}{l}\text { Os cheiros fortes, pois serve para o cérebro nos avisar para evitarmos a } \\
\text { fonte de onde ele vem. }\end{array}$ \\
\hline 11 & $\begin{array}{l}\text { Os odores desagradáveis, pois nosso cérebro interpreta como um sinal de } \\
\text { risco. }\end{array}$ \\
\hline 12 & $\begin{array}{l}\text { As sensações desagradáveis são percebidos mais fácil, pois lembram } \\
\text { perigo ou um ambiente não muito saudável e também riscos à saúd }\end{array}$ \\
\hline 13 & $\begin{array}{l}\text { o mau cheiro, pois ele e mais forte e nos endica que e melhor se afastar } \\
\text { Os cheiros que nos causam sensações desagradáveis, por interpretação } \\
\text { fisiológica. }\end{array}$ \\
\hline 15 & $\begin{array}{l}\text { o cheiro que é identificado de forma mais intensa é o desagradável, e o } \\
\text { nosso cérebro age com a interpretação de que cheiro ruim deve ser perigo } \\
\text { ou ambiente não muito saudável. }\end{array}$ \\
\hline
\end{tabular}

Fonte: Os autores

A partir da análise das respostas dispostas no Quadro 5, evidenciamos que todos os discentes conseguiram respondê-la de forma correta, demonstrando uma boa compreensão e interpretação da questão. Pelas respostas dos estudantes, constamos que ficou claro aos estudantes que nosso corpo registra com maior intensidade o mau cheiro, pois nosso cérebro interpreta esse odor como algo a ser evitado. Constatamos que os estudantes deixam de lado o exercício mecânico de leitura e escrita e apresentam um desenvolvimento cognitivo mais aprofundado (FRANCISCO JUNIOR, 2010). No entanto, ao analisar a resposta do estudante 4, verificamos que é uma cópia literal de informações do parágrafo, o que demonstra que os estudantes ainda apresentam dificuldades em expressar suas ideias quando utilizam frases de sua autoria.

Quanto às questões de interpretação, constatamos que, na primeira atividade de leitura, mais da metade dos estudantes demonstraram dificuldade em responder à questão proposta, apresentando respostas confusas ou mesmo informações não condizentes com a pergunta. Já na questão referente ao último texto, todos os discentes responderam à questão de forma satisfatória, revelando uma excelente interpretação e compreensão do Texto 6 . É importante salientar o papel do professor neste processo, ou seja, sua função de organização pedagógica da leitura, instigando o desenvolvimento de recursos que instiguem os alunos a assumirem uma postura dialógica em relação ao texto, orientando-os a argumentarem sobre sua leitura (FRANCISCO JUNIOR, 2010).

Os estudantes perceberam que o hábito da leitura aprimora as habilidades de interpretação e escrita. Eles puderam observar que as dificuldades iniciais com a nomeação dos parágrafos e questões interpretativas foram superadas ao longo das seis práticas de leitura. Além disso, as práticas periódicas de leitura contribuíram para a atenção e concentração dos alunos ao realizarem as tarefas nesta e em outras disciplinas, algo que foi relatado pelos próprios alunos 
em diferentes ocasiões (formais e informais). Essas afirmações podem ser verificadas nas respostas dos alunos ao questionário que foi aplicado ao término das práticas de leitura.

Estudante 1:" sim, me ajudou a entender melhor os textos de maneira mais fácil, lendo e reelendo cada paragrafo para elaborar um titulo que explicasse o que cada um queria dizer. $E$ para realizar as perguntas tambem ajudou."

Estudante 2: "sim me ajudou muito, porque a interação de parágrafos e a criação de títulos me ajudou a pensar e a interpretar mais facil as questões do proprio texto e tambem na interpretação de outros textos"

Estudante 3:" Sim pois eu aprendi a interpretar melhor e ao mesmo tempo me inteirar dentro de alguns assuntos curiosos e melhorei na gramática."

Estudante 4: "Sim, ajudou-me na minha interpretação, e percebi que desdo inicio era mais difícil fazer agora vi que nos últimos já estava melhor e com mais pratica."

Essa mudança na postura de leitura dos estudantes sugere que eles perceberam que $o$ ato de ler é um processo de interação entre autor-texto-leitor, no qual interferem, entre outros aspectos, as experiências de vida, os valores, as crenças, as relações intertextuais, o conhecimento prévio do leitor, o nível de proximidade deste leitor com o texto, além dos objetivos que orientam o ato de ler, sem deixar de considerar os aspectos análogos referentes ao autor (RÖSING, 2003).

Sobre o desenvolvimento das atividades de leitura possibilitarem uma melhor compreensão dos conteúdos químicos, constatamos que elas apresentam essa potencialidade. Embora os textos não sejam elaborados para discutir os conceitos da disciplina em si, eles proporcionaram uma visão mais ampla da ciência, demostrando ao estudante o quão próximo a ciência está dele e das coisas que ocorrem ao seu redor. Essa mudança de postura foi observada em sala de aula, na evolução do tipo de questionamento e posicionamento no momento da discussão das práticas de leitura. Quando indagados sobre o fato de os textos terem contribuído para o seu aprendizado na disciplina de química eles responderam:

Estudante 9: "Sim, ajudou bastante com os debates em sala de aula com a professora"

Estudante 10: "Acredito que sim, pois foi um ligação entre o texto e o conteúdo que me ajudou até me interessar mais a aprender".

Estudante 11: "Sim, usando coisas do dia a dia ajuda-nos a comparar e a entender melhor por que estudamos química".

Alguns alunos acreditam que sim, os textos são importantes e ajudaram em alguns aspectos dos conteúdos, porém não os julgam fundamentais para compreensão dos conceitos, mas sim complementares a eles:

Estudante 5: "Em parte, pois tendo exemplos do dia-a-dia como os textos facilita, mas se não ter a compreensão do conteúdo não fará diferença."

Estudante 8:" Acredito que alguma coisa sim, mas penso que foi mais fácil compreender os textos através dos conteúdos." 
Com relação ao desenvolvimento das habilidades de leitura e escrita, é importante destacar que é um processo lento, evidenciado ao longo da sequência implementada de práticas de leitura com textos informativos. Portanto, as inserções de atividades de leitura devem ocorrer com regularidade. Para isso, o professor deve ter o cuidado de trazer textos para as aulas que estejam de acordo com o conteúdo a ser trabalhado e com seus objetivos preestabelecidos, mas que também sejam de interesse de seus alunos.

O AVA teve papel importante nas práticas de leitura, pois foi neste ambiente que a docente postou os textos e as atividades de leitura, e os alunos enviaram suas respostas. Costumamos dizer que os alunos desta geração têm maior facilidade no uso das TDIC, contudo isso nem sempre acontece, especialmente se a e tecnologia é utilizada para fins didáticos. Portanto, ao elaborar práticas de leitura em um AVA, conseguimos proporcionar ao estudante uma vivência diferenciada e um aprofundamento dos seus conhecimentos no uso das TDIC não direcionado apenas ao lazer, mas sim contribuindo para a sua aprendizagem. Ainda, o fato de as atividades terem sido realizadas através de um site proporcionou aos alunos inúmeras vantagens, como por exemplo, o fator tempo citado por eles. Com este formato de atividade no AVA, os estudantes se sentem confortáveis para desenvolvê-las com calma, respeitando o seu tempo livre e de aprendizagem, o que, possivelmente, talvez não ocorresse se as mesmas fossem desenvolvidas exclusivamente em sala de aula. Ainda, o AVA auxilia o docente em suas atividades, pois permite a inserção de materiais que tenham o intuito de promover a articulação do conteúdo abordado em sala de aula com assuntos do dia a dia do aluno, algo que nem sempre é aprofundado em sala de aula. Também, o AVA possibilita o controle e avaliação de tarefas postadas pelo professor e enviadas pelos estudantes. Ao serem inquiridos sobre a contribuição do AVA nas atividades de leitura, os estudantes responderam:

Estudante 6: "Sim positivo, porque nos fez interagir com o que o mundo pede hoje em dia, podemos fazer em qualquer lugar, no horário que achamos melhor."

Estudante 7: "Foi, porque assim nos mostra que a internet não é um meio só de acessar as redes sociais, e também podemos de fazer as atividades de sala aula pela internet."

Estudante 13: "Sim, foi algo muito bem pensado. Porque fazer coisas em casa no papel, como é feito normalmente em outras matérias, é cansativo."

Estudante 15:" Foi muito positivo além de ser uma ideia nova de usar essa metodologia melhorando e se preocupando com a questão de poder entender melhor tudo através da interpretação."

Por outro lado, dois estudantes concluíram que as atividades feitas no AVA se tornaram um empecilho para a sua realidade, em função da limitação de acesso à internet. Cabe destacar que, para estes alunos, foram disponibilizados textos e tarefas impressas.

Estudante 12: Mais ou menos. A iniciativa é boa, mas minha internet não colaborava muito.

Estudante 1: Em partes, pois como não tenho internet em casa as vezes fiquei sem entregar no prazo, ainda bem que a professora aceitou, mas achei uma ótima proposta de trabalho. 
Foi solicitado aos estudantes que apontassem fatores negativos que eles observaram em relação aos textos trabalhados. Duas questões se destacaram aqui: o tamanho dos textos, considerados extensos pelos alunos e a sua complexidade. Todos os textos utilizados nas atividades de leitura foram adaptados, justamente por compreendermos que os alunos possuem outras 11 disciplinas para administrar. Não foi nosso intento sobrecarregar os estudantes com textos e questões cansativas, e, por isso o Texto 6 foi o de maior extensão com 6 parágrafos. Dessa forma, acreditamos que a crítica feita pelos estudantes com relação ao tamanho dos textos trabalhados se deva ao fato dos alunos não estarem habituados a práticas de leitura. Sobre a complexidade dos textos, pensamos, ao elaborar as atividades, em atingir diversos níveis de leitura, com textos de linguagem simples (Textos 1 e 2), de nível intermediário (Textos 3 e 4) e outros mais complexos (Textos 5 e 6 ) que auxiliassem a desenvolver as habilidades de leitura, interpretação e escrita por parte dos discentes, dinâmica essa que nos proporcionaria uma visão sobre o nível de leitura de cada aluno em relação ao objetivo e estratégia utilizados.

Acreditamos que as práticas de leitura articuladas ao uso do AVA foram satisfatórias para promover autonomia dos discentes perante o seu processo de aprendizagem. Conforme os textos foram sendo desenvolvidos de forma sistemática e intensiva, foi-lhes proporcionado um modelo de como as atividades poderiam ser elaboradas, permitindo-Ihes ver as "estratégias de ação" em uma situação significativa e funcional (KAUFMAM, 1995).

\section{Considerações Finais}

Os resultados obtidos neste trabalho apontam indícios de avanços dos alunos em relação à leitura e à escrita, havendo uma melhora significativa na capacidade de sintetizar a ideia principal de cada parágrafo e também na elaboração das respostas às questões interpretativas. Apesar das dificuldades apresentadas inicialmente, as atividades de leitura contribuíram para o envolvimento com a leitura, além de possibilitar que os alunos explicitassem suas dúvidas, argumentos e curiosidades (FRANCISCO JUNIOR, 2010).

Assim, a maneira como as atividades de leitura foram aplicadas, acompanhando o desenvolvimento dos conteúdos de Química, com discussões sobre os assuntos abordados nos textos e vinculação com o conteúdo de Química trabalhado, possibilitou a integração do conhecimento dos conteúdos com o conhecimento dos fatos e das notícias abordados nos textos, e ao mesmo tempo promoveu a associação entre a Química e o cotidiano.

Ainda, acreditamos que, para que melhores resultados sejam obtidos, e possíveis dificuldades superadas, é necessário que as práticas de leitura sejam desenvolvidas desde o momento em que os estudantes tenham o primeiro contato com a disciplina de Química, ou seja, no 90 ano do Ensino Fundamental. Afinal, o desenvolvimento das habilidades de leitura, interpretação e escrita associadas ao ensino e aprendizagem em Química é um processo de construção lento e progressivo que requer uma intervenção educativa respeitosa e ajustada por parte do professor, considerando o tempo de aprendizagem e o perfil dos estudantes. 
Portanto, é desejável que as práticas de leitura sejam incorporadas de forma natural em todas as disciplinas da grade curricular, propiciando ao estudante contato com diversos tipos de textos. Dessa forma, as atividades de leitura, quando inseridas nas aulas de química, podem favorecer o desenvolvimento de habilidades orais e de escrita, além de estabelecer relações com o conhecimento científico, criando a oportunidade de desenvolvimento de habilidades capazes de levar o aluno a construções de manifestações próprias, podendo também contribuir para que reconheçam a Química como uma construção humana.

$O$ destaque deste trabalho é o caráter diferenciado da prática de leitura, que procurou articular o uso do texto informativo em um AVA e a abordagem de conteúdos químicos mediante o uso de estratégia de leitura. Essa nova forma de trabalhar a leitura de texto informativo nas aulas de Química se diferencia dos trabalhos reportados na literatura, conforme indica o levantamento bibliográfico discutido neste estudo.

Além disso, percebemos que a forma de trabalho propostas para os distintos textos informativos motivaram os alunos a participarem das atividades de leitura nas aulas. Durante as discussões dos textos, percebemos ainda que os alunos se interessaram pelos temas abordados, apresentaram dúvidas, questionamentos, novas informações que muitas vezes iam além daquelas contidas no texto, embora estivessem relacionadas ao seu tema. Isso demonstra o interesse e motivação dos alunos em relação às informações veiculadas nos textos estudados, no seu cotidiano ou até mesmo nos meios de comunicação. Ressaltamos que a proposta de uso recorrente e sistemático de atividades que envolvam textos informativos em aulas de Química aliada ao uso das TDIC, detalhada neste artigo, mostrou ser um caminho possível para estabelecer relações entre o conteúdo científico e temas relacionados ao cotidiano, assim como para o desenvolvimento das habilidades de leitura e escrita.

Entendemos que o uso do AVA foi fundamental para o desenvolvimento deste trabalho, pois, potencializaou o desenvolvimento e/ou aprimoramento das habilidades de leitura e interpretação, despertou o gosto pela leitura, o interesse e a motivação dos estudantes. Isto ficou evidente, pelo comprometimento e pontualidade no envio das tarefas de leitura no AVA, ainda, quando os estudantes foram questionados sobre a forma como as atividades de leitura foram organizadas no AVA, eles relataram que seria "cansativo" se as mesmas fossem realizadas da forma tradicional, ou seja, em folhas impressas. Os discentes reconhecem que, na atualidade, é necessário dominar as TDIC, a fim de conseguir um melhor desenvolvimento na sua formação acadêmica, ou mesmo, uma melhor colocação no mercado de trabalho. Além disso, se sentem familiarizados com o computador, o celular e outras ferramentas tecnológicas, pois é por meio delas que intereagem com familiares e amigos nas redes sociais, realizam pesquisas escolares, dentre outras atividades rotineiras, como por exemplo, a própria leitura através de ebooks, que são mais funcionais e mais baratos quando comparados com a versão impressa. Reconhecessemos que o acesso a internet, no contexto de escolas públicas estaduais, pode ser um problema para muitos estudantes. No entanto, consideramos que em nosso trabalho, possivelmente, os resultados não seriam tão promissores como os apresentados, caso não utilizássemos um AVA. 


\section{Referências}

BARDIN, L. Análise de conteúdo. Lisboa: Edição 70, 2004.

BRASIL. Indicador de Alfabetismo Funcional. Relatório de Resultados Preliminares 2018. Disponível em: https://drive.google.com/file/d/1ez-6jrIrRRUm9JJ3MkwxEUffltjCTEI6/view Acesso em: 12 de jul. 2020

CALÇADE, P. O Brasil está mesmo alfabetizado? 2019. Disponível em: https://novaescola.org.br/conteudo/15927/o-brasil-esta-mesmo-alfabetizado Acesso em: 13 de jul. 2020

CORREIA, D.; DECIAN, E.; SAUERWEIN, I. Leitura e argumentação: potencialidades do uso de textos de divulgação científica em aulas de Física do ensino médio. Ciência \& Educação, Bauru, v. 23, n. 4, p. 10171034, 2017.

FAILLA, Z. (org). Retratos da Leitura no Brasil 4. Rio de Janeiro: Sextante, 2016. Disponível em: http://plataformadolivro-com-br.umbler.net/2019/retratos.php. Acesso em: 31 de jul. 2020

FERREIRA, L. N. A; QUEIROZ, S. L. Autoria no ensino de química: Análise de Textos Escritos por Alunos de Graduação. Ciência e Educação, n. 3, p. 541-558, 2011.

FREIRE, P. A Importância do ato de ler. 47ed. São Paulo: Cortez Editora, 2006.

GIORDAN, M. Análise e Reflexões sobre os Artigos de Educação em Química e Multimídia Publicados entre 2005 e 2014. Química Nova na Escola, [s.I.], v. 37, n. 2, p.154-160, dez. 2015.

JUNIOR, W.E.F. Estratégias de Leitura e Educação Química: Que relações? Química Nova Na Escola. Vol. 32, $N^{\circ} 4$, nov.2010.

SANTOS JUNIOR, J. B.; FILHO, E. B.; CAVAGIS, A. D. M.; ANUNCIAÇÃO, E. A. Um estudo comparativo entre a atividade experimental e a simulação por computador na aprendizagem de eletroquímica. Revista Electrónica de Enseñanza de Las Ciencias, [s.I.], v. 15, n. 2, p.312-330. 2016.

KAUFMAM, A. M.; RODRÍGUEZ, M. H.. Escola, leitura e produção de textos. Porto Alegre: Artmed,1995.

KLEIMAN, A. B. Oficina de leitura: teoria e prática. Campinas: Pontes, 2004.

LEITE, B. S. Tecnologias no ensino de química: Teoria e Prática na formação docente. Curitiba: Appris, 2015. $365 \mathrm{p}$.

LIBERATO, Y; FULGÊNCIO, L. É Possível Facilitar a Leitura: um Guia para Escrever Claro. São Paulo: Editora Contexto, 2007.

MACHADO, A. S. Uso de Softwares Educacionais, Objetos de Aprendizagem e Simulações no Ensino de Química. Química Nova na Escola, [s.I.], v. 38, n. 2, p.104-111, maio 2016.

MENEGASSI, R. J. Perguntas de leitura. In: MENEGASSI, R. J. (Org.). Leitura e ensino. 2.ed. Maringá: Eduem, 2010b. p.167-189.

MORENO, E. L.; HEIDELMANN, S. P. Recursos Instrucionais Inovadores para o Ensino de Química. Química Nova na Escola, [s.I.], v. 39, n. 1, p.12-18, 2017.

PAULA, A. C.; VERGARA, L.; LUZ, R. M.; VIALI, L.; LAHM, R. Softwares educacionais para o ensino de física, química e biologia. Revistas Ciências e Ideias, Rio de Janeiro, v. 5, n. 1, p.106-121, abr. 2014.

PAULETTI, F.; ROSA, M. P. A.; CATELLI, F. A importância da utilização de estratégias de ensino envolvendo os três níveis de representação da Química. Revista Brasileira de Ensino de Ciência e Tecnologia, [s.I.], v. 7, n. 3, p.121-134, dez. 2014.

RÖSING, T. M. K. A formação do professor e a questão da leitura. Passo Fundo: UPF Editora, 2003. 
SOLÉ, I. Estratégias de leitura. 6. ed. Porto Alegre: Artmed, 1998.

Recebido em agosto de 2019.

Aprovado para publicação em agosto de 2020.

\section{Ciléia Rodrigues}

Pós - Graduação - Doutorado - Programa de Pós - Graduação em Educação em Ciências: Química da Vida e Saúde, Universidade Federal de Santa Maria (UFSM), Rio Grande do Sul, RS, Brasil, cileiarodrigues@yahoo.com.br

\section{Daniele Correia}

Instituto de Química, Programa de Pós-Graduação em Ensino de Ciências, Universidade Federal de Mato Grosso do Sul (UFMS), Mato Grosso do Sul, MS, Brasil, d.correia@ufms.br

\section{Ricardo Andreas Sauerwein}

Departamento de Física, Programa de Pós-Graduação em Ensino de Ciências: Química da Vida e Saúde, Universidade Federal de Santa Maria, Santa Maria, RS, Brasil, rsauer.ufsm@gmail 